\title{
Complete Survey of Wind Behavior over the Arabian Gulf
}

\author{
Hussam Khonkar \\ King Abdulaziz City for Science and Technology (KACST) \\ Energy Research Institute (ERI) \\ P.O. Box 6086, Riyadh, Saudi Arabia, 11442 \\ khonkar@kacst.edu.sa
}

\begin{abstract}
The purpose of this communication is to give the prospective of wind energy over the Arabian Gulf. Various offshore developments have been taking place over the past years; one in particular is the research and development of wind energy. This has lead to an increased demand of reliable data for wind speed and its direction. In this paper, we study the behavior of wind speed and direction over the Arabian Gulf. The data used for the analysis covers the years 1960 to 2007, provided by the International Comprehensive Ocean-Atmosphere Data Set (ICOADS). Previous research over the Arabian Gulf shows that average wind speed for example in the month February is at $5.83 \mathrm{~m} / \mathrm{s}$. Whereas, this analysis shows that for the similar month the average has increased to $7.77 \mathrm{~m} / \mathrm{s}$ with an improvement of $25 \%$. Hence, this determines a significant improvement in the wind behavior over the Arabian Gulf.
\end{abstract}

\section{Introduction}

The Arabian Gulf is a semi-enclosed sea (Fig. 1) located between $24^{\circ} \mathrm{N}$ $30^{\circ} \mathrm{N}$ latitude and $48^{\circ} \mathrm{E}-56^{\circ} \mathrm{E}$ longitudes. The total area is around $239,000 \mathrm{~km}^{2}$ (Ahmad and Sultan, 1991). British Admiralty surveys on the Gulf made between 1823 and 1935 produced navigational charts (Emery, 1956); this could be considered as the beginning of scientific work over the Gulf region.

The study area (Fig. 1) which covers $24^{\circ} \mathrm{N} / 29^{\circ} \mathrm{N}-48^{\circ} \mathrm{E} / 56^{\circ} \mathrm{E}$ has with one degree resolution a total number of 36 grid points over water. The data provided by ICOADS data is typically collected from merchant 
ships that pass through the channel. The data is statistically formatted for each month of each year, with respect to longitude and latitude.

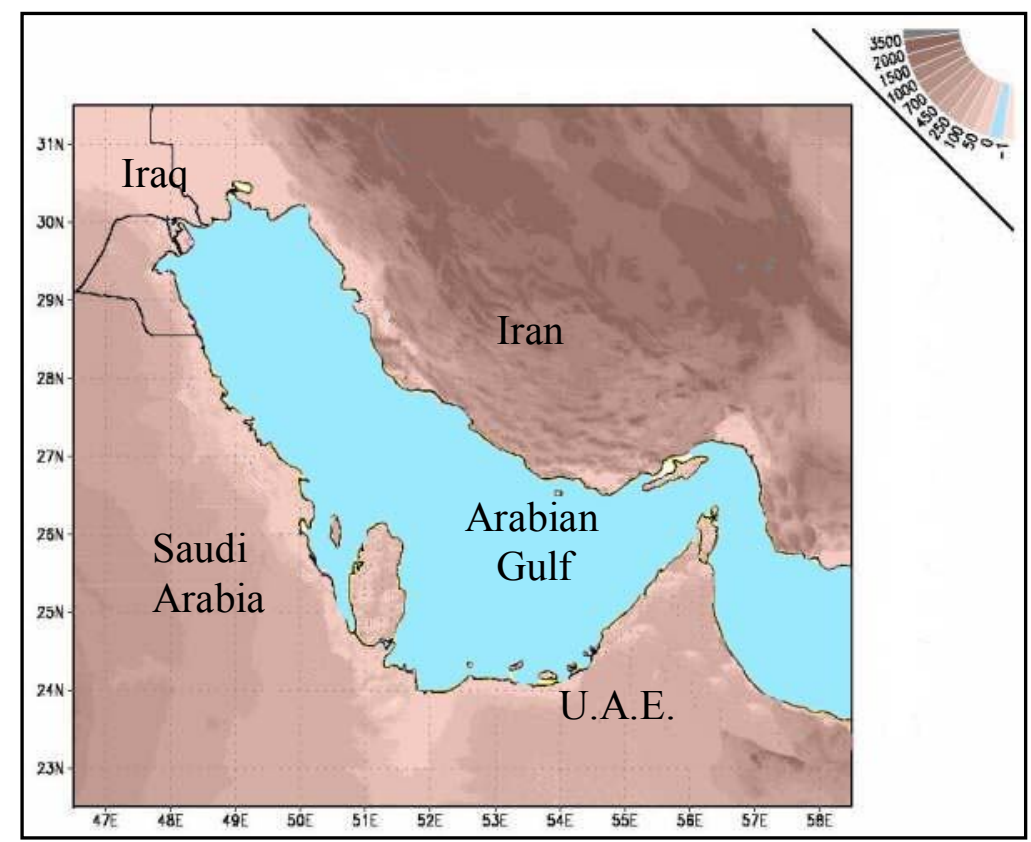

Fig. 1. Topographic map for the Arabian Gulf (height in meter).

The west of the Arabian Gulf is surrounded by an arid area, with a dominant wind that blows over the Gulf from the North and the NorthWest directions.

The west coastline and the southern part of the Gulf have a broad area of shallow continental shelf compared to the east side. Meteorological and climatological information are important for utilizing any kind of energy. This research provides information/data that will assist in finding the most suitable locations to produce energy and to focus on areas of highest resources of renewable energy over the Gulf water.

Wind energy has gained considerable value as a renewable energy source in Arabian Gulf (Rehman Shafiqur, 2006). It is strongly recommended for maintaining a clean environment. Wind energy has a little impact offshore. Wind energy is one of Europe's largest indigenous energy resources (Troen and Petersen 1989); the use of energy by Europeans is predicted to rise from $50 \%$ to $70 \%$ by 2030 . Wind power 
stations can be constructed and they deliver power far quicker than any other conventional source. Already today, wind power built in Europe is saving 50 million tones of $\mathrm{CO}_{2}$ every year. The Arabian Gulf is considered as one of the most important and precious energy resources in the world, motivates keeping its environment clean with less carbon emissions.

The most interesting and famous weather phenomenon of wind blowing all around the year in the Gulf is from the North-West (NW) (Fig. 2-1, 2-2). The wind from North-West in winter is stronger than summer; this season lasts from November to March and reaches its maximum during December to February. The North-West wind commonly occurs following a cold front. In contrast, the summer NorthWest wind is weak and lasts from the beginning of June to the end of July (Murty and Al-Sabh, 1988).

\section{Climatological Renewable Energy}

Many methods used to collect meteorological grid data of monthly mean from daily-totals. The most straightforward and accurate method would be to establish a measurement network with a weather station located at each grid point. To cover the requirements of the Gulf requires a huge number of stations. This could be done only after the final selection of a construction site for a power plant based on the data from wind atlas, and taking into account other factors such as distance to load centers.

There is a maintained meteorological data set by Saudi Arabian Presidency of Meteorology and Environment (PME), which covers the period of the last three decades for twenty nine stations in the Kingdom. The stations are spread over the major part of Saudi Arabia except the maritime zone and the Rubelkhali (Empty Quarter), which are completely devoid of any measurement, other than the one in the coastal cities. Most of the data is not compiled for many stations, and some of the data are missing or not well archived.

The data from twenty-nine PME stations during the period of 19701982 was analyzed on a daily basis to compute monthly mean wind speed. Samples of accurate data for the major cities inland are illustrated below (Fig. 2). 


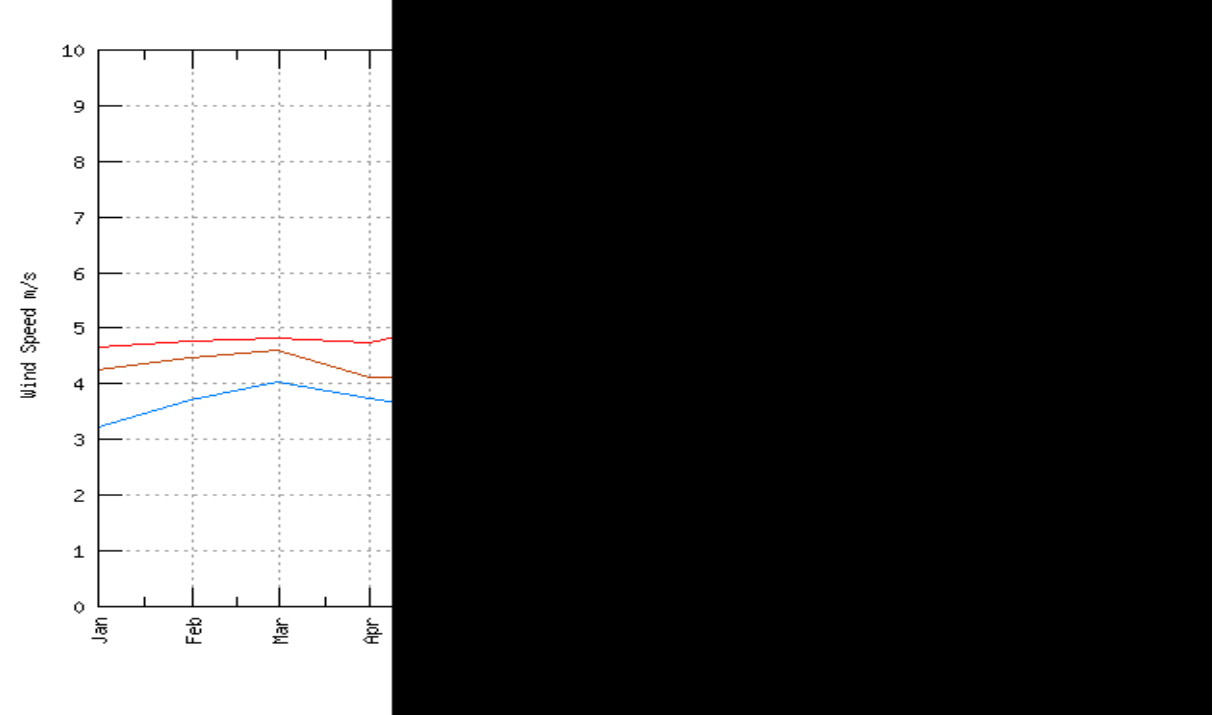

Fig. 2. Average wind speed over three major cities in Saudi Arabia.

\section{Data Processing}

The global monthly mean observed wind speed (U-component East West and V-component North South) provided by ICOADS has been processed and analyzed in this study. ICOADS data formatted in a yearmonth summary; and is gridded into $1^{\circ}$ latitude by $1^{\circ}$ longitude coordinates. The available data provided by ICOADS is from 1960 to 2007 (47 years).

During the initial Processing of the data, there were irregular missing data in space and time. The possible factors for missing data identified for example; voluntary ships that passed through certain location coordinates performed data collection. It is possible that missing data were not their point of interest and hence no data for that point was recorded. Additionally there is no incentive for ships to collect data and this leads to the fact that ships are not responsible for the equipment maintenance or its malfunction. The analysis showed that there was data that was uncharacteristic of the wind behavior over certain months and location hence questioned its accuracy.

Before going on data analysis, the following assumptions are made:

1. Determine the standard deviation of readings, if the standard deviation is equal to zero, and then eliminate the reading. Rationale: A 
reading with zero standard deviation suggests that all values obtained were identical; furthermore, there was only one reading associated with the value.

2. To determine a monthly behavior of mean wind speed over a certain month, there has to be at least 30 observations. Rationale: 30 observations would average one observation per day of the certain month.

\section{Data Analysis}

The analysis and the description of the general pattern of wind speed are performed in two steps:

1. Calculation of mean monthly wind speed from 1960 to 2007.

2. Calculation of wind speed distribution using Weibull probability density function.

The Mean monthly wind speed and direction is calculated according to the following steps:

a) Take the sum of all monthly mean observed value (U-component East West and V-component North South) in each grid.

b) Divide by the number of observation.

The calculations of mean Monthly are shown below:

U mean $\quad=\left(\sum\right.$ of U-component $) /($ Number of observation of Ucomponent)

$\mathrm{V}$ mean $\quad=\left(\sum\right.$ of $\mathrm{V}$-component $) /($ Number of observation of $\mathrm{V}-$ component)

Wind speed $=\left[(\text { Umean })^{2}+(\text { Vmean })^{2}\right]^{1 / 2}$

Wind direction $=\operatorname{atan}($ Umean $/$ Vmean $)$

\section{Results}

\section{Mean Monthly Wind Speed}

The analysis of mean monthly wind speed and direction are shown in Fig. (2-1 \& 2-2) and reveal that the direction of wind speed is NorthWest over the year. Winter wind is stronger than summer wind. This season lasts from November to March. Comparatively, the summer wind is weak and the season lasts from the beginning of June to the end of 
August. The average wind speed over some area of Gulf shore for the months of November to March are $5.39 \mathrm{~m} / \mathrm{s}, 7.27 \mathrm{~m} / \mathrm{s}, 7.35 \mathrm{~m} / \mathrm{s}, 6.26 \mathrm{~m} / \mathrm{s}$ $\& 5.85 \mathrm{~m} / \mathrm{s}$ respectively. Similarly, in the same location over the months of June and July the average wind speed is $6.60 \mathrm{~m} / \mathrm{s} \& 5.96 \mathrm{~m} / \mathrm{s}$ respectively. Although most of the Gulf area in the summer has a low wind speed, (there exist other areas of moderate wind speed such as central Gulf). For example, the coastal line of Saudi Arabia during June and July has average winds at $5.73 \mathrm{~m} / \mathrm{s} \& 4.80 \mathrm{~m} / \mathrm{s}$ respectively (grid point located at longitude 50 and latitude 27). This variation of wind is caused by many factors that are discussed later and related to data collection methods or by locality such as topography.

The general conclusion from the analysis of mean monthly wind speed supports that stronger wind speeds are observed over the months of November to February.

\section{Wind Speed Distribution}

It is very important for the Turbine designers to describe the General Pattern of Wind Speed Variations to be able to optimize the design of their turbines and estimate their income from electricity generation.

To describe the pattern of wind, usually, the two-parameters of Weibull (1951) probability density function is used to represent wind speed distributions. This distribution is often used in wind energy engineering, as it conforms well to the observed long-term distribution of mean wind speeds for a range of sites. This distribution is given by the following equation

$$
f(U)=\frac{k}{A}\left(\frac{U}{A}\right)^{k-1} \exp \left(-\left(\frac{U}{k}\right)^{k}\right),
$$

where $k$ is the non dimensional shape parameter or slope and $A$ the scale parameter. This expression is valid for $k>1$, and $A>0$.

The Weibull probability density function expresses the probability $f$ $(U)$ to have a wind speed $U$ during the years. To estimate the values of the two parameters $A$ and $k$ of Weibull distribution the method of maximum likelihood estimator will be used. The method of maximum likelihood based on the calculation of the joint probability of the observations assuming independent and identically distributed observations. 

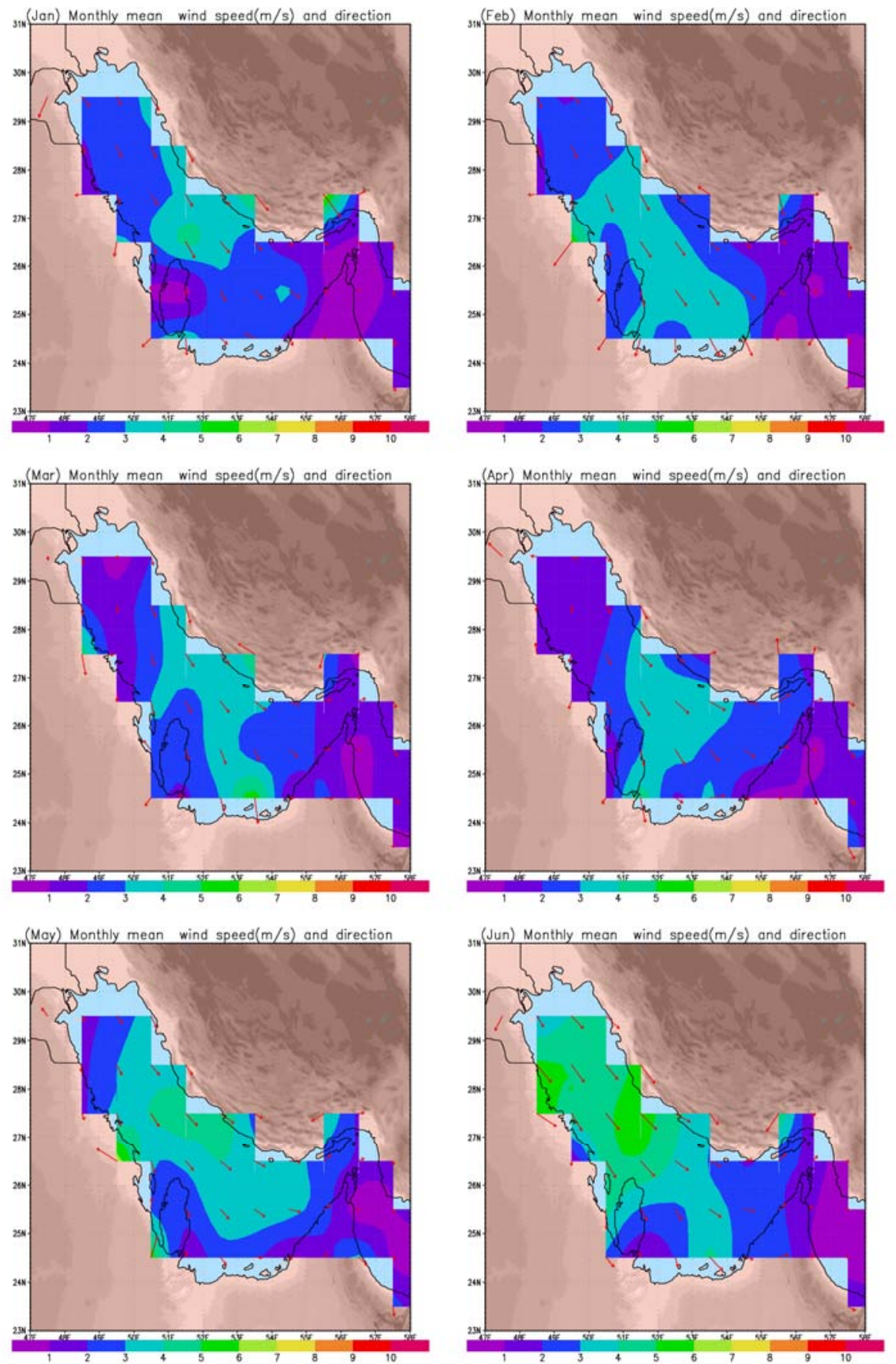

Fig. 2-1. Monthly mean wind speed (m/s shaded) and direction. 

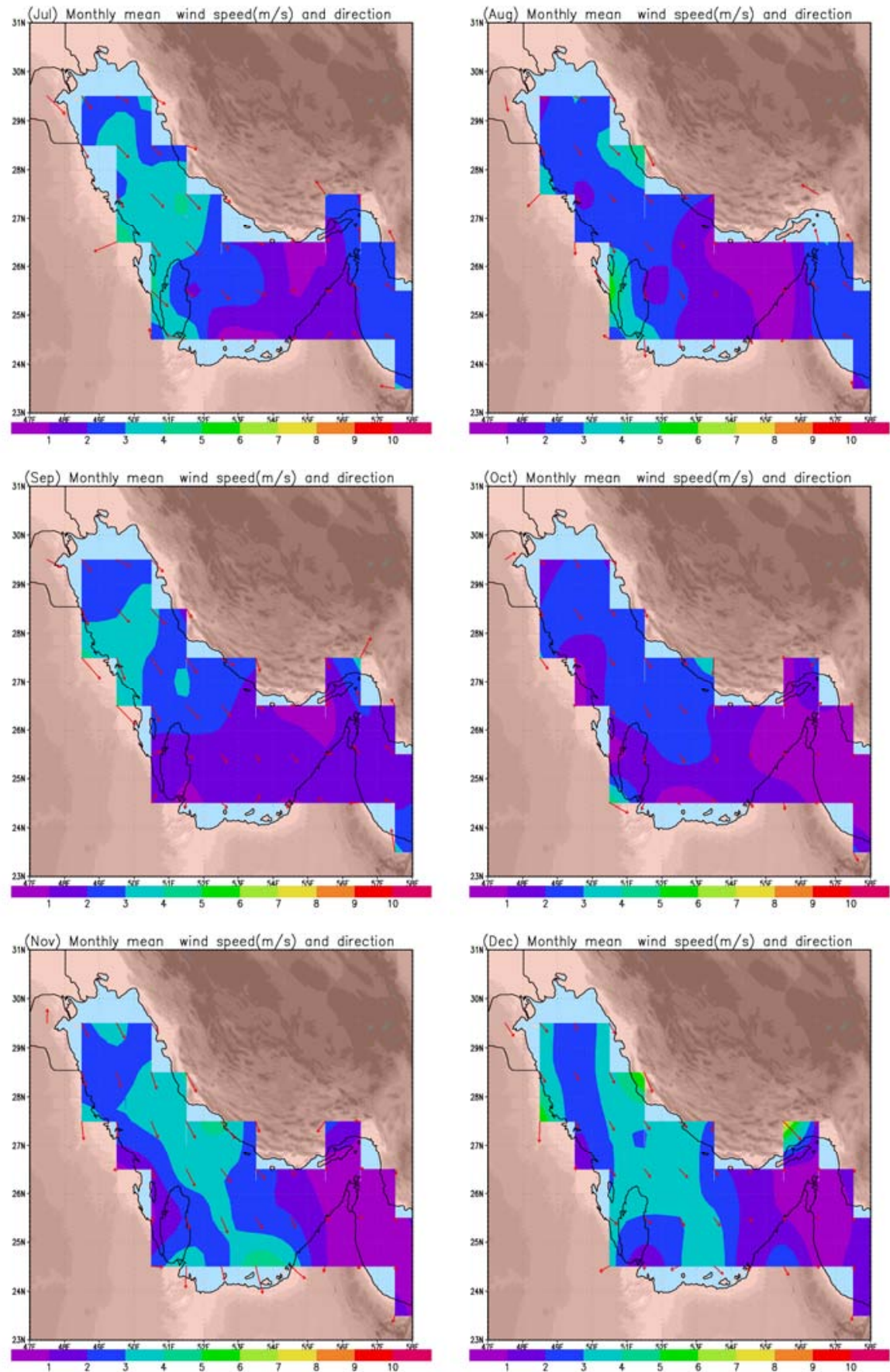

Fig. 2-2. Monthly mean wind speed (m/s shaded) and direction (red arrows). 
The wind speed probabilities estimated by Weibull are a function of $A$ and $k$, this joint probability is a function of these parameters. The estimated mean wind speed takes the form:

Mean wind speed value $=A \Gamma\left(1+\frac{1}{k}\right)$

where $\Gamma$ is the gamma function defined as $\Gamma(x)=\int_{0}^{\infty} t^{x-1} e^{-t} d t$

Also the available wind power density $\mathrm{E}$, which is proportion to cubic mean wind speed

$$
E=\frac{1}{2} \rho A^{3} \Gamma\left(1+\frac{1}{k^{3}}\right)
$$

Where $E$ is power density $\left(\mathrm{W} / \mathrm{m}^{2}\right)$ and $\rho$ is air density $(\sim 1.225)$ $\mathrm{kgm}^{-3}$ for a temperature $15^{\circ} \mathrm{C}$ and a standard pressure $1013 \mathrm{mb}$.

The monthly mean values of $A, k$, wind speed and energy are analyzed and plotted in Fig. 3-1 to 3-4. The figures show that the shape factor will typically range from one to three. For a given average wind speed, a lower shape factor indicates a relatively wide distribution of wind speeds around the average while a higher shape factor indicates a relatively narrow distribution of wind speeds around the average.

A lower shape factor will normally lead to a higher energy production for a given average wind speed.

Also the actual mean wind speed differs from these estimated values by Weibull as much as $25 \%$, depending on the actual wind speed distribution (or Weibull $k$ value) this difference is associated with some uncertainties in observing data.

Figures 3-1 to 3-4 show the maximum energy concentrated along the Gulf shore, this is due to terrain orientation and features that affect the prevailing wind direction and speed which will heavily affect the energy. For example, ridgelines that are perpendicular to the prevailing wind direction are preferred to ridgelines that are parallel to the prevailing wind direction (United Arab Emirate, U.A.E.).

Figure 4-1 shows sample of monthly wind speed distribution at selected grid points. We will notice that in most areas, strong force winds are rare, while moderate (wind speed 4-6 $\mathrm{m} / \mathrm{s}$ ) and fresh winds (wind speed $>6 \mathrm{~m} / \mathrm{s}$ ) are quite common. 

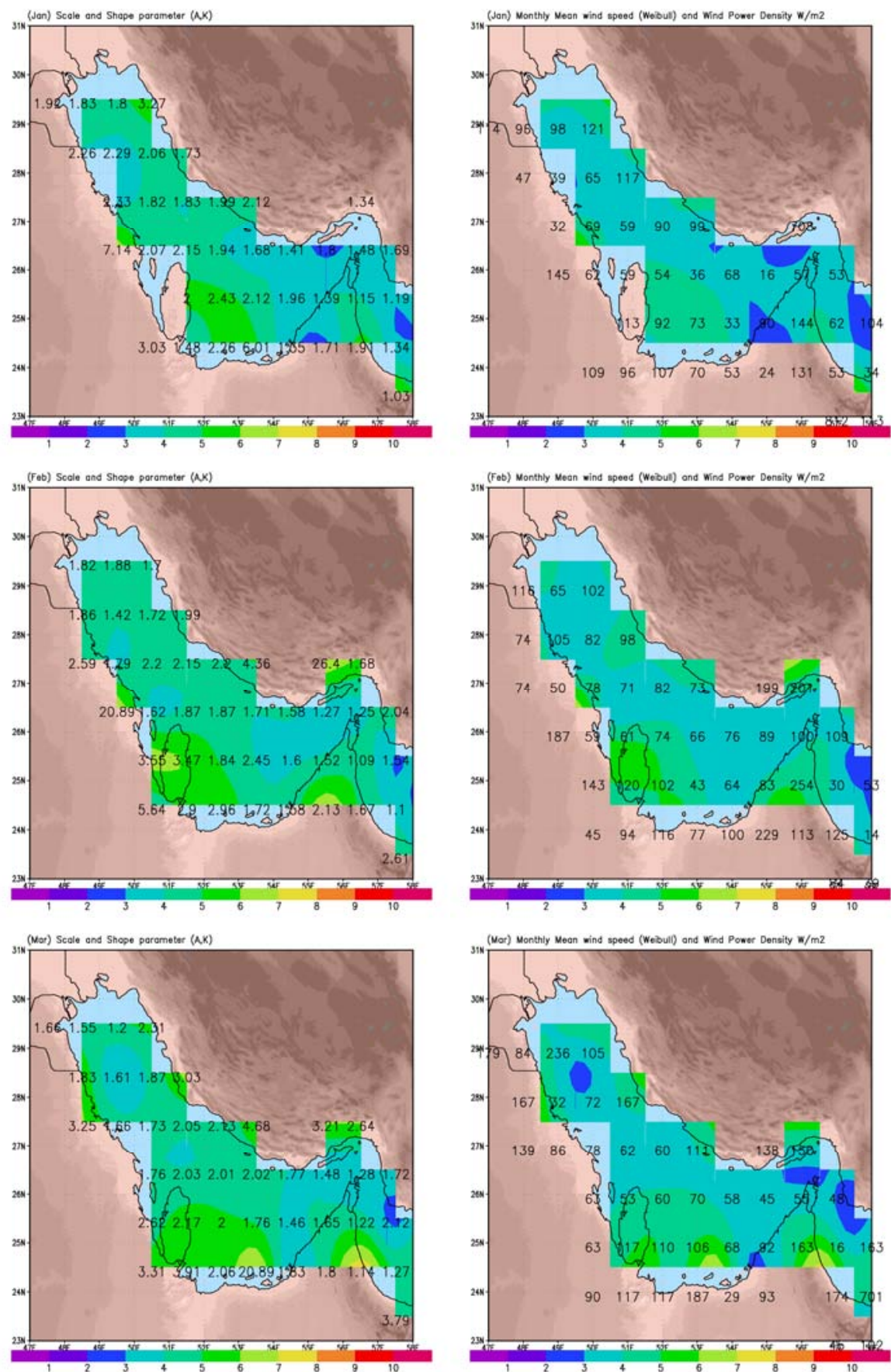

Fig. 3-1. Left monthly mean shape parameter $A$ (shaded) and scale $k$ values). Right monthly mean wind (shaded) and energy (values). 

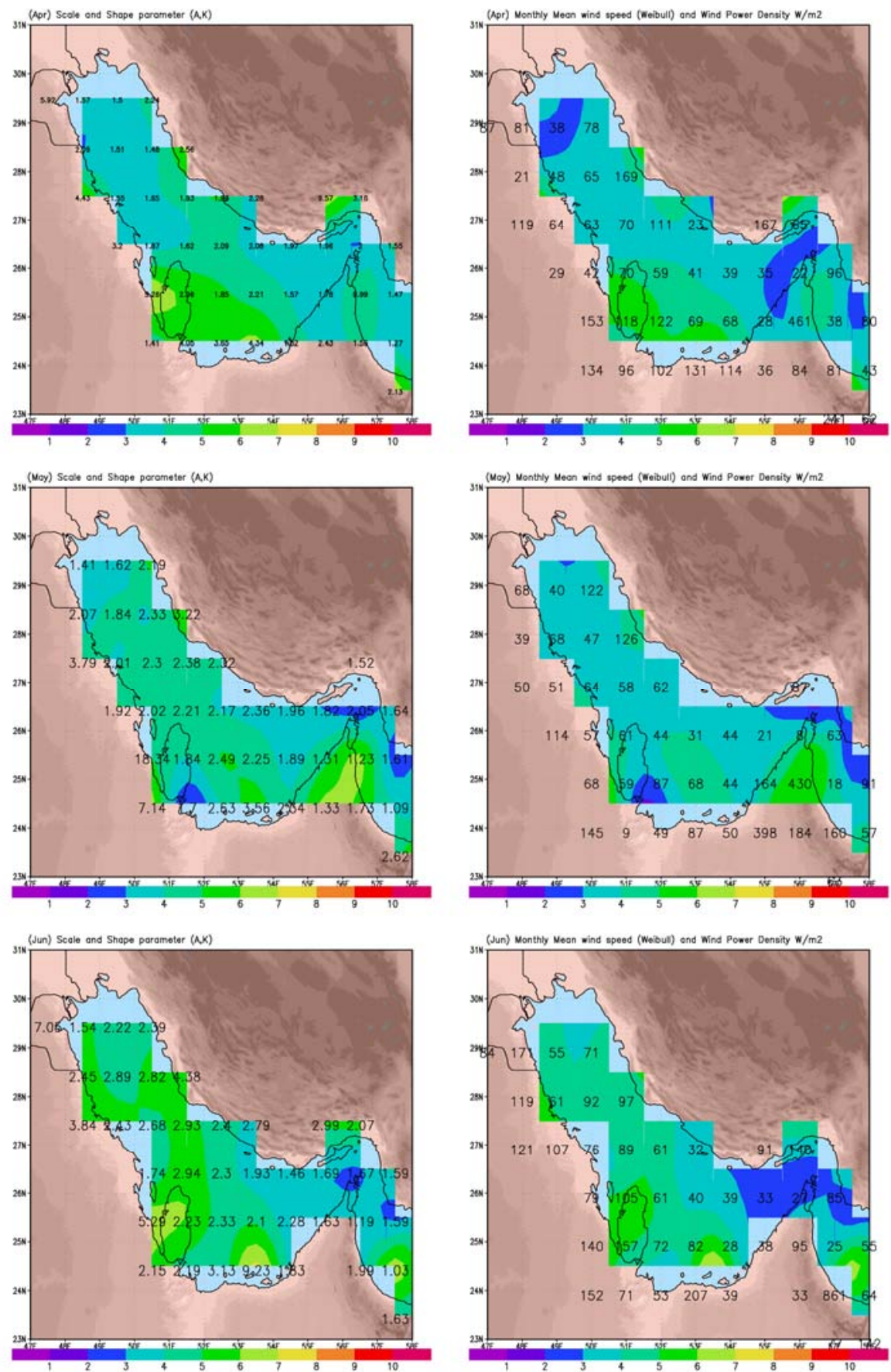

Fig. 3-2. As shown in Fig.3-1. 

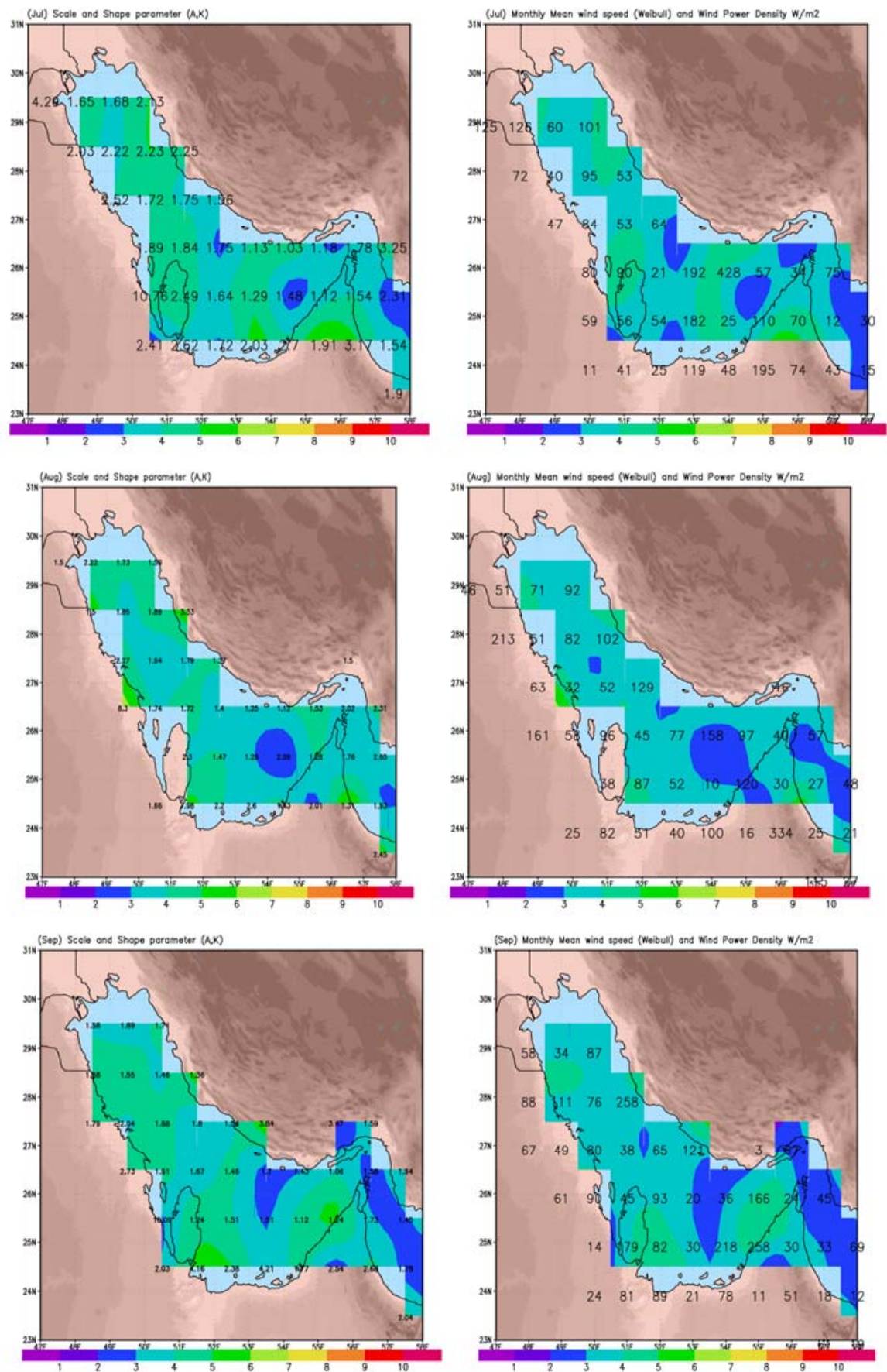

Fig. 3-3. As shown in Fig.3-1. 

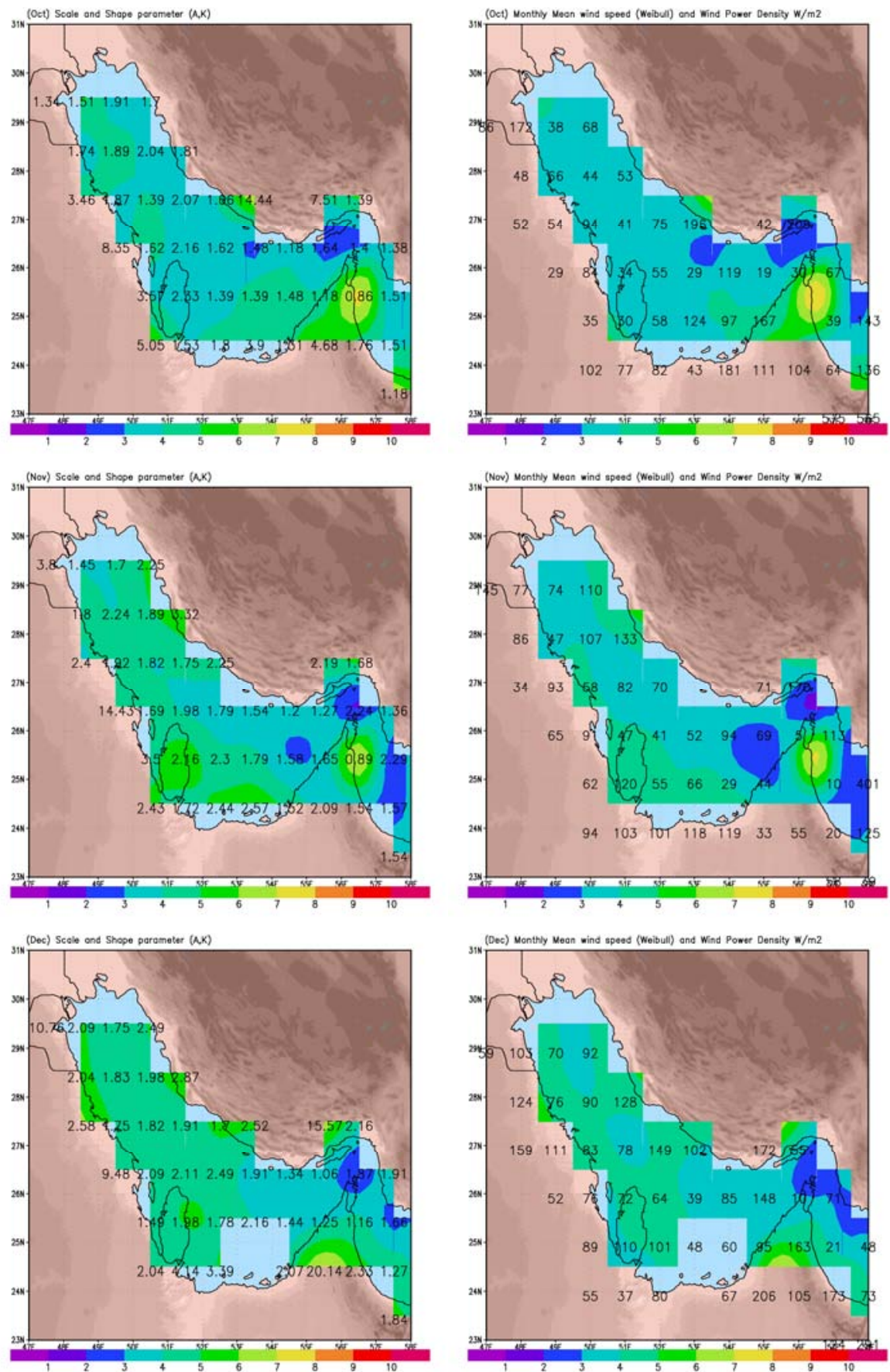

Fig. 3-4. As shown in Fig. 3-1. 

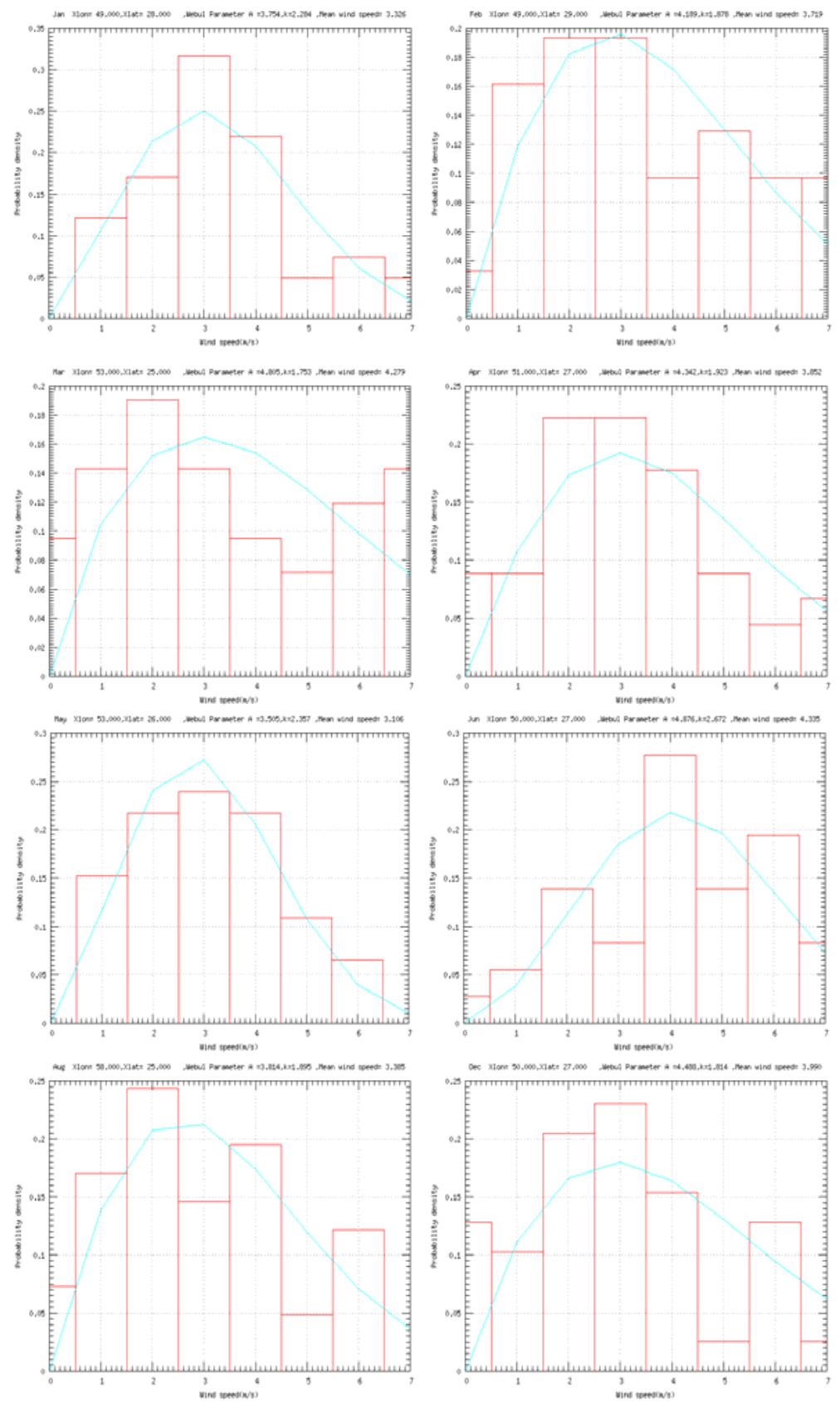

Fig. 4. Sample of wind speed distribution over some arbitrary selected grid point at different months. 


\section{Economic Advantages \& Disadvantages}

What are the advantages of this study? This study brings collective information of the wind behavior over the Arabian Gulf and shows prospective locations at which to develop a wind farm. Studies show that offshore winds are higher than on-shore winds and this study is a development in that area. Other benefits for offshore development of wind farms include: 1) Wind farms are less noticeable offshore; 2) Minimum Noise produced by the wind farms; 3) Taller wind towers; and 4) Higher wind speeds. What is a good wind speed? Studies have shown that these wind generators are practically efficient at $4.5 \mathrm{~m} / \mathrm{s}$ and higher. In essence, it is necessary to have a constant wind flow. Therefore, an ideal location would be offshore. However, with certain advantages, there are a few disadvantages. 1) Offshore development is expensive because of the increased cost in off-shore installations, 2) Increased cost in transferring power from offshore site, 3) May require higher voltage operation, and 4) Possibility of tower corrosion due to water environment.

Even though there are certain advantages and disadvantages in the wind farm technology. However, the fact remains the same that there is a strong contender in maintaining a clean environment and helps in energy production while reducing the average costs.

\section{Conclusion \& Future Work}

This study is an initial step suggesting typical wind behavior over the Arabian Gulf. Our study shows that with the current amount of data, we have seen high trends of wind speed. Over the study area (45 grid points) months such as November, December, January and February have shown the highest wind speeds. The averages are $5.39 \mathrm{~m} / \mathrm{s}, 7.27 \mathrm{~m} / \mathrm{s}, 7.35 \mathrm{~m} / \mathrm{s} \&$ $6.26 \mathrm{~m} / \mathrm{s}$ respectively. This also leads to safe state that a wind farm is a prospective renewable energy resource and wind behavior over the Arabian Gulf will supply efficient wind resources to justify the assets.

Future work includes certain revisions, these include:

1. Revise data collection methods. Data collecting stations need to be setup in certain onshore and offshore locations to ensure data completeness. 
2. Another years of data needed to strengthen the research of wind behavior in the Arabian Gulf.

3. Identify the most windy areas and setup stations for hourly data collection.

\section{Acknowledgment}

I would like to express my full gratitude to Dr. George A. Maul and the Department of Marine \& Environmental Systems for providing the required resources necessary towards the completion of this research study.

Special thanks to Mr. T. Puri, Mr. M. Hussein and Mr. A. Gumgumji for assisting me in the research and successfully accomplishing all tasks assigned.

\section{References}

Ahmad, F. and Sultan, S.A.R. (1991) Annual mean surface heat fluxes in the Arabian Gulf and the net heat transport through the Strait of Hormuz, Atmosphere-Ocean, 29: 54-61.

Emery, K.O. (1956) Sediments and water of the Persian Gulf, Bulletin of the American Association of Petroleum Geologists, 40(10): 2354-2383.

Murty, T.S. and Al-Sabh, M.I. 1988) A Review of the Physical Oceanographic Characteristics in the Inner Gulf, the Kuwait Action Plan (KAP) Region, Unpublished manuscript from Dr. Mohammed A.M. Rady, The Faculty of Marine Sciences, King Abdulaziz University, Jeddah, Saudi Arabia.

Rehman, Shafiqur (2006) Offshore Wind Power Assessment on the East Coast of Saudi Arabia, Center for Engineering Research, Research Institute, King Fahd University of Petroleum and Minerals Wind Engineering, 29: 409-420.

Troen, I. and Petersen, E.L. (1989) European Wind Atlas, ISBN 87-550-1482-8, Risø National Laboratory, Roskilde. 656 p., Data disk incl.

Weibull, W. (1951) A Statistical Distribution Function of Wide Applicability, ASME Journal of Applied Mechanics, 18(3): 293-297. 


\section{مسح شامل لسلوك الرياح على الخليج العربي}

\section{حسام إبر اهيم خنكار}

مدينة الملك عبد العزبز للعلوم والنكنولوجيا، معه أبحاث الطاقة ص.ب.7 1 • 7 ، الرياض، المملكة العربية السعودية، khonkar@kacst.edu.sa

المستخلص. تساهم هذه الورقة في إعطاء التصور عن مدى كفاءة

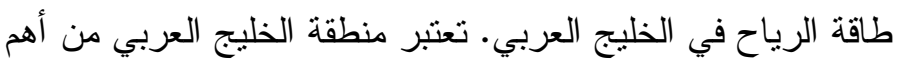

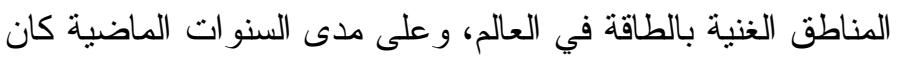

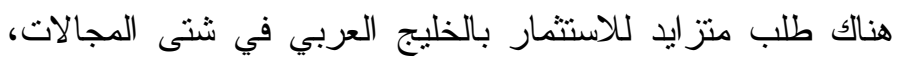

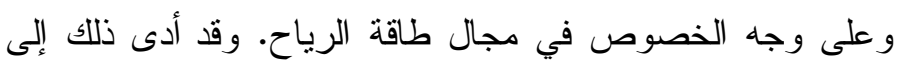
زيادة الطلب على البيانات الموثقة لسرعة الرياح، واتجاهها في الخليج العربي. ففي هذه الورقة تم دراسة سلوك سرعة الرياح

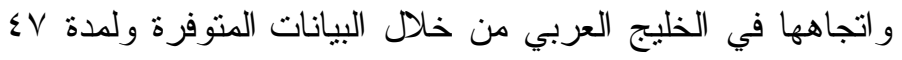

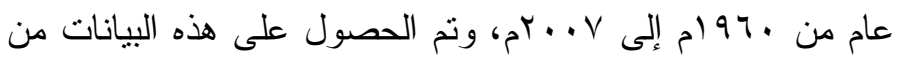
International Comprehensive Ocean-Atmosphere Data Set (ICOADS)

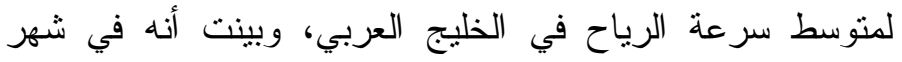

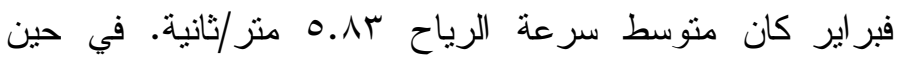

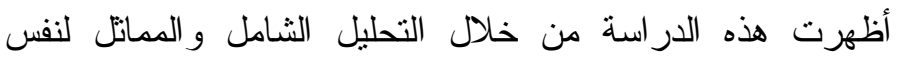

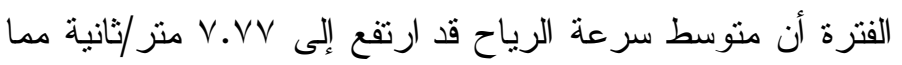

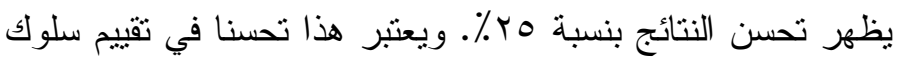
سر عة الرياح في الخليج العربي. 